\title{
BLUE STAIN IN LUMBER INDUSTRY AND LOSSES CAUSED BY CUTTING METHODS
}

\author{
Osman Komut \\ Gumushane University \\ Gumushane, Turkey \\ (Received May 20I9)
}

\begin{abstract}
In this study, it is aimed to determine the waste and productivity losses of Scots pine (Pinus sylvestris L.) logs that were exposed to blue stain degradation. In this context, a total of 39 timber production processes were analyzed in 7 different lumber managements using prism cutting and sharp cutting method. The main product yield and additional processing requirements were determined for flawed and flawless logs in blue stain damage. As a result of the study, it was determined that the blue stain degradation decreased the main product efficiency by $17 \%$ in the prism cutting method and by $33 \%$ in the sharp cutting method. Statistically significant differences were discovered between the efficiency values obtained as a consequence of cutting flawed and flawless logs with prism and sharp cutting methods. In addition, additional processing requirements were determined in the sharp mowing method.
\end{abstract}

KEYWORDS: Blue stain, scots pine log, lumber productin, loss of productivity.

\section{INTRODUCTION}

The processing of wood-based products supplied from forest resources in such a way that will minimize waste has a significant contribution to the sustainability of forest resources (Kantay and Köse 2009, Khalili et al. 2015). A considerable part of wood-based plants in forests are not suitable for use in industrial production. On the other hand, there is a vast scale of loss during the conversion of the obtained wood products to the final products (Gladstone and Ledig 1990). While the use of efficient and profitable production methods is increasing the likelihood of economic success of managements, it will reduce the consumption pressure on forest resources (Fuwape 2001, Sloan and Sayer 2015).

Significant raw material losses occur during the processing phase of logs (Eshun et al. 2010). It is reported that these losses can reach to approximately $80 \%$ beginning from cuttings of the tree to the final product (Dionco-Adetayo 2001, Eshun et al. 2012). That most of these wastes are not used directly for industrial production reduces the added value potential of the resources and 
leads to significant economic losses. However, it is known that there is a considerable amount of hardship in reducing the waste amount in the lumber industry (Eshun et al. 2015).

As well as the heterogeneous structure of the wood material, its nature is easily affected by environment and storage conditions which have important effects on the losses occurring during the processing of logs (Blanchette et al. 1989, Şen et al. 2018). On the other hand, factors like the production technique, the suitability of the machine-equipment used and the competence of machine operator increase these losses (Daian and Ozarska 2009, Tunçel and Koç 2017).

Logs are exposed to many harmful effects such as foremost discoloration, crack formation, dote and insect damage until they are taken to production in the forest industry managements (Kantay and Köse 2009, Ahmad et al. 2018). Discoloration of wood material may occur due to different reasons such as sunlight, humidity, temperature, contact with metals and microorganisms (Tolvaj et al. 2011, Li et al. 2019). Fungi are reported to be effective on about one third of the annual industrial wood production (Örs and Keskin 2001, Hong et al. 2019). Especially the blue stain degradation caused by the effect of fungus in the sapwood part of coniferous wood logs leads to significant losses due to its rapid development and visual anomalies it causes (Örs and Keskin 2001). On the other hand, the waste amount generated during the processing of the logs depends on the production method and the technological foundation, hence it depends on the production efficiency (FAO 2014, Gligoraş and Bor 2015). The waste amount in question may vary between different companies in the same country (FAO 2014).

In this study, it is aimed to determine the waste amount generated during the industrial processing of Scots pine logs exposed to sapwood discoloration and their productivity loss in the context of the production method variable.

\section{MATERIAL AND METHODS}

The study was carried out in 7 small and medium-sized lumber production managements operating in Gumushane province, Turkey. The said forest industry managements provide their raw material needs from planted tree sale auctions conducted by the Forestry Directorate of Gümüşhane and Torul affiliated to the General Directorate of Forestry. In the study, the production process of 7 managements, 3 of which use the sharp cutting method and 4 use the prism cutting method, were examined.

Although discoloration and mold fungi do not affect the structural features of wood, the deterioration they cause leads to aesthetic and economic losses (Zeleniuc 2008). In this study, the effects of blue staining caused by coloring fungi on the sapwood part of Scots pine (Pinus sylvestris L.) logs were investigated. In this context, firstly, the defect detected in the logs was measured as shown in Fig. 1 and calculated by Eq. 1: (Komut and et al. 2013).

$$
\text { Degradation width }=\left(\sum^{n}{ }_{m}={ }_{1} x_{m}\right) / n
$$

Prism and sharp cutting methods were applied for the production of flawed with blue staining - flawed in terms of appearance (FTA) and flawless without blue staining (flawless in terms of appearance (FssTA) in the processing of Scotch pine logs (Fig. 2). Prism cutting method is preferred in the production of lumber with equal width; sharp cutting method is preferred in timber production with equal thickness (Colakoglu and Colak 2003). 


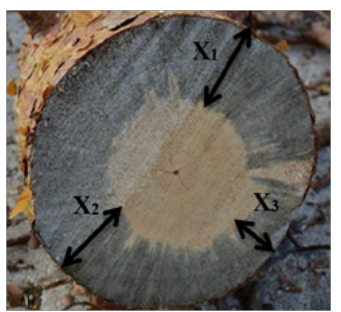

Fig. 1: Cross-section of the blue stained log and the measurement of degradation width (Komut and Ozturk 2018).
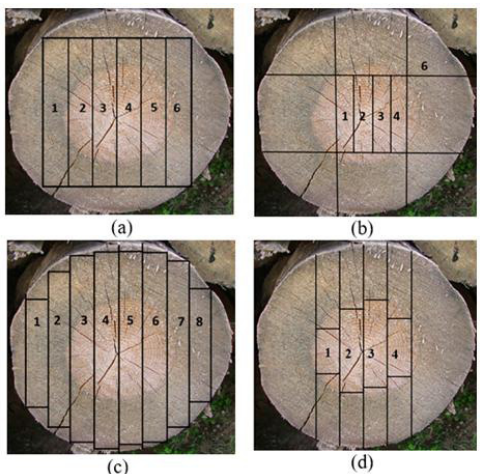

Fig. 2: Cutting methods used in efficiency calculation (a) FTA timber production with rism cutting method, (b) FssTA timber production with Prism cutting method, (c) FTA timber production with sharp cutting method, (d) FssTA timber with sharp cutting method.

Eq. 2 was used to calculate the production efficiency for timber obtained with different production methods.

$$
R=\frac{V_{l o g}}{\sum_{x=1}^{n} e_{x} \cdot g_{x} \cdot l_{x}}
$$

where: $\quad R$ - production efficiency $(\%), V_{\log }-\log$ volume $\left(\mathrm{cm}^{3}\right), e_{x}$ - lumber thickness $(\mathrm{cm})$, $g_{x}$ - lumber width $(\mathrm{cm}), l_{x}$ - lumber length $(\mathrm{cm})$.

Additional processing was observed to be performed in the side pick-up and multi-slitting machines in order to remove the degraded part of the FTA timbers obtained from logs exposed to blue staining. In the study, the durations (energy consumption and labor times) required by the additional procedures were measured with the help of a stopwatch.

IBM SPSS $(20,0)$ package program was used in the analysis of data concerning cutting methods. In the study, since the number of samples was less than 30, Mann-Witney U test with two independent variables from non-parametric tests was used (Kalayc1 2010). Microsoft Office Excel 2010 package program has been utilized to make comparisons of frequency, ratio etc. 


\section{RESULTS AND DISCUSSION}

\section{Findings regarding the managements using prism cutting method}

In this study, the efficiency values obtained during the process of cutting of healthy and blue stained logs in 4 different lumber managements by prism cutting method are given in Tab. 1 . A total of 9 cleaned (not irrigated) round wood pieces, which was obtained as a result of processing of FssTA Scotch pine logs, was measured and the average main product efficiency was calculated as 59\%. For the timber production of FssTA timber by cleaning the part with blue staining in cross section area, 14 logs were cut, and the main product efficiency value was determined as $42 \%$.

Tab. 1: The efficiency values obtained in Prism cross-cutting method.

\begin{tabular}{|c|c|c|c|c|c|c|c|}
\hline Workplace & $\begin{array}{c}\log \\
\text { diameter } \\
(\mathrm{cm})\end{array}$ & $\begin{array}{l}\text { Log length } \\
\text { (m) }\end{array}$ & $\begin{array}{l}\text { Measured } \\
\text { distortion } \\
(\mathrm{cm})\end{array}$ & $\begin{array}{c}\text { Total } \\
\text { volume } \\
\left(\mathrm{m}^{3}\right)\end{array}$ & $\begin{array}{l}\text { Main } \\
\text { product } \\
\text { volume } \\
\left(\mathrm{m}^{3}\right)\end{array}$ & $\begin{array}{c}\text { Main } \\
\text { product } \\
\text { efficiency } \\
(\%)\end{array}$ & $\begin{array}{c}\text { Main product } \\
\text { efficiency loss } \\
(\%)\end{array}$ \\
\hline \multirow{7}{*}{1} & 32 & 3 & 0 & 0.241 & 0.154 & 64 & 0 \\
\hline & 30 & 3 & 5 & 0.212 & 0.135 & 44 & 15 \\
\hline & 26 & 3 & 7 & 0.159 & 0.101 & 34 & 25 \\
\hline & 42 & 3 & 7 & 0.416 & 0.265 & 44 & 15 \\
\hline & 45 & 3 & 10 & 0.477 & 0.304 & 39 & 20 \\
\hline & 36 & 3 & 0 & 0.305 & 0.194 & 59 & 0 \\
\hline & 43 & 3 & 0 & 0.436 & 0.277 & 60 & 0 \\
\hline \multirow{5}{*}{2} & 27 & 2 & 4 & 0.115 & 0.073 & 46 & 13 \\
\hline & 32 & 2 & 0 & 0.161 & 0.102 & 62 & 0 \\
\hline & 28 & 2 & 0 & 0.123 & 0.078 & 55 & 0 \\
\hline & 37 & 2 & 5 & 0.215 & 0.137 & 48 & 11 \\
\hline & 35 & 2 & 5 & 0.192 & 0.123 & 47 & 12 \\
\hline \multirow{6}{*}{3} & 20 & 3 & 4 & 0.094 & 0.060 & 41 & 18 \\
\hline & 28 & 3 & 7 & 0.185 & 0.118 & 36 & 23 \\
\hline & 26 & 3 & 0 & 0.159 & 0.101 & 58 & 0 \\
\hline & 35 & 3 & 0 & 0.289 & 0.184 & 55 & 0 \\
\hline & 28 & 3 & 8 & 0.185 & 0.118 & 32 & 27 \\
\hline & 31 & 3 & 9 & 0.226 & 0.144 & 32 & 27 \\
\hline \multirow{5}{*}{4} & 45 & 3 & 10 & 0.477 & 0.304 & 39 & 20 \\
\hline & 26 & 3 & 0 & 0.159 & 0.101 & 57 & 0 \\
\hline & 22 & 3 & 0 & 0.114 & 0.073 & 58 & 0 \\
\hline & 38 & 3 & 5 & 0.340 & 0.217 & 48 & 11 \\
\hline & 56 & 3 & 5 & 0.739 & 0.470 & 53 & 6 \\
\hline
\end{tabular}

* Average product efficiency was taken as 59\%.

In the prism cutting method, the efficiency loss for the main product is observed to increase as the blue stained area width and the log diameter increase in the log cross section (Fig. 3). On the other hand, differences were observed between the 4 managements in terms of average main product efficiency (respectively 50.2\%, 53\%, 43\%, 51\%). 


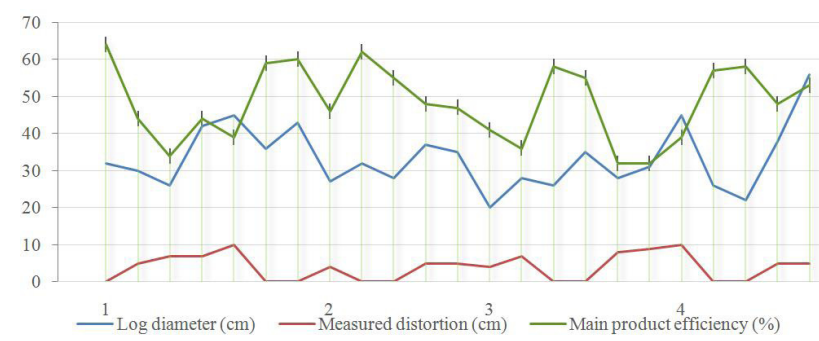

Fig. 3: The effect of discoloration on the efficiency of the main product in the prism cutting method.

\section{Findings concerning the managements using sharp cutting method}

In the study, efficiency values obtained by cutting FTA and FssTA sample logs with sharp cutting method are given in Tab. 2. Six of processed logs were FssTA Scots pine logs, while 10 of them was selected as FTA logs. The average efficiency of non-irrigated lumber produced as a result of cutting of FssTA logs with sharp cutting method is calculated as $71 \%$. The average efficiency of the main product for logs cleared from non-irrigated and stained parts produced from the damaged logs was determined as $38 \%$.

Tab. 2: The efficiency values obtained in the application of sharp cutting method.

\begin{tabular}{|c|c|c|c|c|c|c|c|}
\hline Workplace & $\begin{array}{c}\log \\
\text { diameter } \\
(\mathrm{cm})\end{array}$ & $\begin{array}{l}\text { Log length } \\
\text { (m) }\end{array}$ & $\begin{array}{l}\text { Measured } \\
\text { distortion } \\
(\mathrm{cm})\end{array}$ & $\begin{array}{c}\text { Total } \\
\text { volume } \\
\left(\mathrm{m}^{3}\right)\end{array}$ & $\begin{array}{l}\text { Main } \\
\text { product } \\
\text { volume } \\
\left(\mathrm{m}^{3}\right) \\
\end{array}$ & $\begin{array}{c}\text { Main } \\
\text { product } \\
\text { efficiency } \\
(\%)\end{array}$ & $\begin{array}{c}\text { Main } \\
\text { product } \\
\text { efficiency } \\
\text { loss (\%) }\end{array}$ \\
\hline \multirow{6}{*}{1} & 40 & 3 & 4 & 0.377 & 0.215 & 57 & 14 \\
\hline & 35 & 3 & 6 & 0.289 & 0.115 & 40 & 31 \\
\hline & 31 & 3 & 6 & 0.226 & 0.095 & 42 & 29 \\
\hline & 30 & 3 & 5 & 0.212 & 0.072 & 34 & 37 \\
\hline & 34 & 3 & 0 & 0.272 & 0.207 & 76 & 0 \\
\hline & 28 & 3 & 0 & 0.185 & 0.133 & 72 & 0 \\
\hline \multirow{6}{*}{2} & 27 & 3 & 9 & 0.172 & 0.041 & 24 & 47 \\
\hline & 28 & 2 & 8 & 0.123 & 0.032 & 26 & 45 \\
\hline & 33 & 2 & 12 & 0.171 & 0.050 & 29 & 42 \\
\hline & 36 & 2 & 10 & 0.204 & 0.081 & 40 & 31 \\
\hline & 29 & 2 & 0 & 0.132 & 0.087 & 66 & 0 \\
\hline & 30 & 3 & 0 & 0.212 & 0.146 & 69 & 0 \\
\hline \multirow{4}{*}{3} & 42 & 4 & 0 & 0.554 & 0.399 & 72 & 0 \\
\hline & 26 & 4 & 5 & 0.212 & 0.096 & 45 & 26 \\
\hline & 32 & 3 & 7 & 0.241 & 0.094 & 39 & 32 \\
\hline & 32 & 3 & 0 & 0.241 & 0.166 & 69 & 0 \\
\hline
\end{tabular}

*Average efficiency of the main product is taken as $71 \%$.

In the logs cut by the sharp intersection method, as the log diameter increased, while the main production efficiency increased, the increase in the measured decay limited the increase in productivity (Fig. 4). 


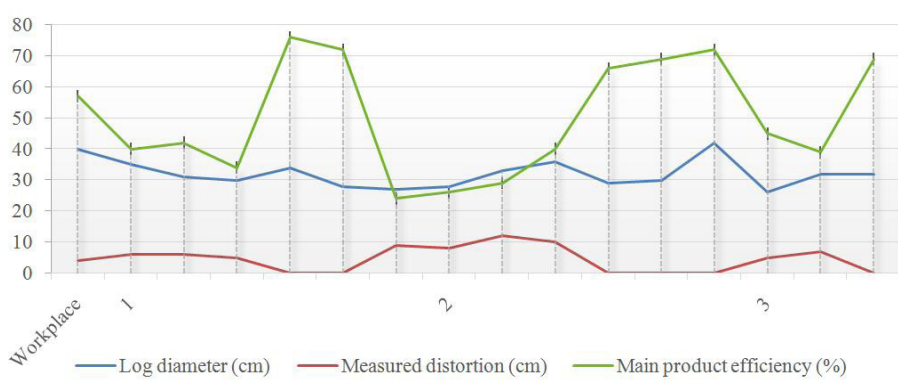

Fig. 4: The effect of color change on the main product efficiency in sharp cutting method.

\section{Findings concerning the comparison of prism cutting-sharp cutting methods}

In this study, 15 FssTA and 24 FssTA Scots pine logs were ensured to be cut in 7 different managements. Of these logs, 23 were cut with prism and 16 were cut with sharp cutting method. The mean width of the discoloration on the cross-sectional surface of the cut logs was $6.5 \mathrm{~cm}$ in the prism cutting method and $7.2 \mathrm{~cm}$ in the sharp cutting method. There were statistically significant differences $(p<0.05)$ in terms of efficiency and waste ratio between the cutting of logs with and without the blue stain degradations with the prism and sharp cutting method (Tab. 3). The cutting method used is observed as one of the factors affecting the production efficiency (Alvarez and Vera 2014). It is reported that the differences in productivity between managements occur as a result of the usage of inefficient processes and methods as well as the lack of equipment (Adhikari and Ozarska 2018, Eshun et al. 2012). On the other hand, there are studies that report results regarding that decrease in efficiency may depend on the properties of the suplied log (Örs and Keskin 2001, Choi et al. 2013, Pang et al. 2015).

Tab. 3: Mann-Whitney U test results concerning the cutting method during the processing of logs.

\begin{tabular}{|c|c|c|c|c|c|c|c|}
\hline Variable & $\begin{array}{l}\text { Cutting } \\
\text { Method }\end{array}$ & $(\mathrm{N})$ & $\begin{array}{l}\text { Mean } \\
\text { Rank }\end{array}$ & $\begin{array}{c}\text { Mann- } \\
\text { Whitney U }\end{array}$ & $\begin{array}{c}\text { Wilcoxon } \\
\text { W }\end{array}$ & Z & $\begin{array}{c}\text { Asymp. Sig } \\
\text { (2-tailed) }\end{array}$ \\
\hline \multirow{3}{*}{$\begin{array}{l}\text { Efficiency Loss } \\
\text { for Flawed Logs }\end{array}$} & Prism Cutting & 14 & 8.29 & \multirow{3}{*}{11.00} & \multirow{3}{*}{116.00} & \multirow{3}{*}{-3.458} & \multirow{3}{*}{$0.001^{*}$} \\
\hline & Sharp Cutting & 10 & 18.40 & & & & \\
\hline & Total & 24 & & & & & \\
\hline \multirow{3}{*}{$\begin{array}{l}\text { Efficiency for } \\
\text { Flawless Logs }\end{array}$} & Prism Cutting & 9 & 5.00 & \multirow{3}{*}{0.00} & \multirow{3}{*}{45.00} & \multirow{3}{*}{-3.193} & \multirow{3}{*}{$0.001^{*}$} \\
\hline & Sharp Cutting & 6 & 12.50 & & & & \\
\hline & Total & 15 & & & & & \\
\hline
\end{tabular}

"p $<0.05$

While the production efficiency was higher in the sharp cutting method in the FssTA logs, thus the waste amount was lower, the efficiency loss occurred during the cutting of FTA logs was higher. The efficiency in the timber production process varies significantly depending on the log defects. In order to increase the efficiency, it is important to determine these defects correctly (Todoroki 2003). Fungus-originated color changes also affect the log quality (Vanzetti et al. 2018). However, although it is not considered as a log defect, the change in log diameter and length is also reported to be effective on the efficiency thereby on losses (Yang and Jenkins 2008, Vanzetti et al. 2018). 


\section{Findings concerning other losses}

The FTA obtained from the logs cut with the sharp cutting method has been shown to require additional processing in the multi-slitting machine to remove this flaw. The distance of the additional processing machines to the main processing machine was measured as $4 \mathrm{~m}$ in management 1 , as $5.5 \mathrm{~m}$ in management 2 and as $6.5 \mathrm{~m}$ in management 3 . According to this, transport times, machine processing and additional stacking times of timber were measured for additional processing (Tab. 4). In the production of aesthetically flawless lumber by cutting a total of 10 logs with blue-stained degradation in three managements, a work loss of $47.73 \mathrm{~min}$ was calculated. On the other hand, an additional 20.07 min machine processing time has formed.

Tab. 4: Measurements for additional processing times.

\begin{tabular}{|c|c|c|c|c|c|c|c|c|}
\hline Workplace & $\begin{array}{c}\text { Log } \\
\text { diameter } \\
(\mathrm{cm})\end{array}$ & $\begin{array}{c}\text { Log } \\
\text { length } \\
(\mathrm{m})\end{array}$ & $\begin{array}{c}\text { Measured } \\
\text { distortion } \\
(\mathrm{cm})\end{array}$ & $\begin{array}{c}\text { Number } \\
\text { of timber } \\
(\text { width 3 } \\
\mathrm{cm})\end{array}$ & $\begin{array}{c}\text { Transport } \\
\text { time to } \\
\text { machine } \\
(\mathrm{min})\end{array}$ & $\begin{array}{c}\text { Processing } \\
\text { time (min) }\end{array}$ & $\begin{array}{c}\text { Re-stacking } \\
\text { time (min) }\end{array}$ & $\begin{array}{c}\text { Total } \\
\text { lost time } \\
(\mathrm{min})\end{array}$ \\
\hline \multirow{4}{*}{1} & 40 & 3 & 4 & 7 & 2.57 & 4.08 & 2.33 & 8.98 \\
\cline { 2 - 10 } & 35 & 3 & 6 & 5 & 1.83 & 2.92 & 1.67 & 6.42 \\
\cline { 2 - 10 } & 31 & 3 & 6 & 5 & 1.83 & 2.92 & 1.67 & 6.42 \\
\cline { 2 - 10 } & 30 & 3 & 5 & 5 & 1.83 & 2.92 & 1.67 & 6.42 \\
\hline \multirow{3}{*}{2} & 27 & 3 & 9 & 1 & 0.50 & 0.47 & 0.33 & 1.30 \\
\cline { 2 - 10 } & 28 & 2 & 8 & 3 & 1.50 & 1.40 & 1.00 & 3.90 \\
\cline { 2 - 9 } & 33 & 2 & 12 & 1 & 0.50 & 0.47 & 0.33 & 1.30 \\
\hline \multirow{3}{*}{3} & 36 & 2 & 10 & 3 & 1.50 & 1.40 & 1.00 & 3.90 \\
\cline { 2 - 9 } & 26 & 4 & 5 & 3 & 1.80 & 1.75 & 1.00 & 4.55 \\
\hline \multirow{2}{*}{ Total } & 32 & 3 & 7 & 3 & 1.80 & 1.75 & 1.00 & 4.55 \\
\hline
\end{tabular}

In the sharp cutting method, the production efficiency decreases as the cross sectional area of the flawed part and color degradation measured horizontal to the log section increases with increase in the obtained log amount. On the other hand, the increase in total loss time duration remains limited. In this application, it was observed that the number of obtained flawless lumber increased as the loss time increased (Fig. 5). There are a number of studies reporting that the insect damage, crack etc cause significant economic losses due to losses in the production process (Zeleniuc 2008, Loeffler and Anderson 2018, Vanzetti et al. 2018).

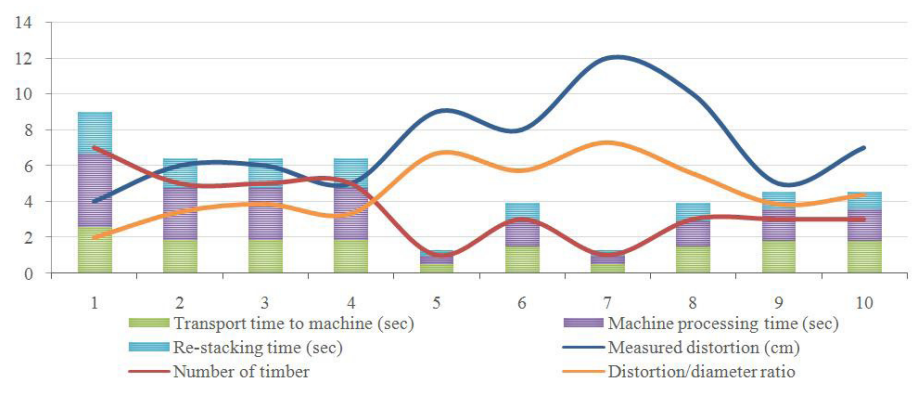

Fig. 5: Total number of flawless lumbers, degradation amount and lost time condition according to the the ratio of degradation to the cross-sectional area variables. 
As the number of timbers that require additional processing and the timber length increase, the lost time increases. On the other hand, as the degradation on the cross-sectional surface of the timber increases, the number of flawless lumber obtained decreases, thus decreasing the lost times (Fig. 6).

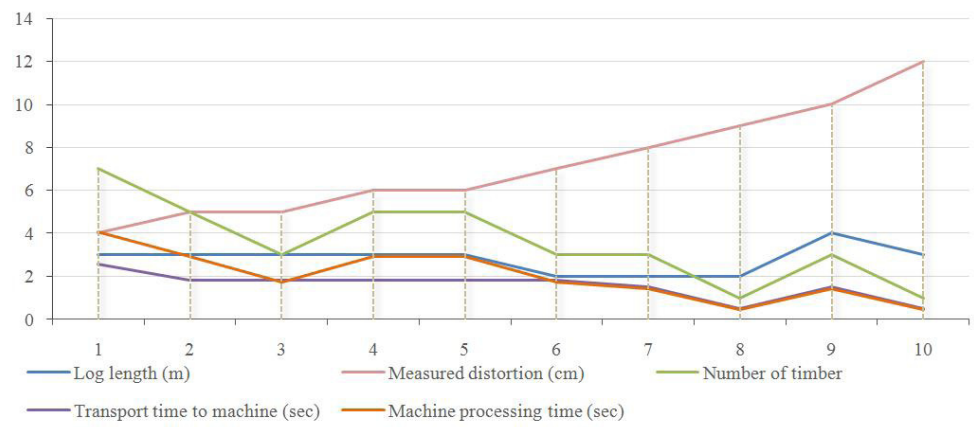

Fig. 6: The effect of lumber length, number and degradation amount on lost time.

\section{CONCLUSIONS}

Blue stain is the appearance defect that can develop in all production and waiting processes of wood material. Blue stain greatly increases the loss in the timber industry sector, therefore leads to a decrease in the main product yield. The amount of loss occurs at a higher level at the sharp cutting method than the prism cutting method. If sharp cutting is chosen as the cutting method, the occurrence of additional production processes causes an increase in economic losses. On the other hand, differences in the main product efficiency may occur in different managements using the same production method.

It is clear that the most effective way to prevent loss is to prevent the formation of blue staining. Therefore, an effective and efficient inventory control system can reduce waiting times (Zeleniuc 2008). However, the application of the prism cutting method for the blue stained logs as well as the preference for the logs with low sapwood width will benefit for a decrease in the losses. The efficient and effective usage of the products obtained from forest resources will contribute greatly to the sustainability of these resources.

\section{REFERENCES}

1. Adhikari, S., Ozarska, B., 2018: Minimizing environmental impacts of timber products through the production process "From Sawmill to Final Products". Environmental System Research 7: 6.

2. Ahmad, A., Elserogy, A., Al-Muheisen, Z., Villeneuve, F., El-Oqlah, A., 2018: The conservation of a wooden nabataean coffin box from Jordan-application of non-destructive ultrasonic technique. Wood Research 63(1): 2018: 1-14.

3. Alvarez, P.P., Vera, J.R., 2014: Application of robust optimization to the sawmill planning problem. Annals of Operations Research 219: 457-475. 
4. Blanchette, R.A., Nilsson, T., Daniel, G., Abad, A., 1989: Biological degradation of wood. Chapter 6, Pp. 141-174, Archaeological Wood.

5. Choi, S.I., Kang, H.M., Lee, C.K., Sato, N., 2013: Study on current status and task of sawmills located in the woodland of korea. Journal of the Faculty of Agriculture Kyushu University 58(1): 183-190.

6. Çolakoğlu, G., Çolak, S., 2003: Molding techniques lecture notes, Karadeniz Technical University Faculty of Forestry Course Lecturers, Series No: 70, Trabzon.

7. Daian, G., Ozarska, B., 2009: Wood waste management practices and strategies to increase sustainability standards in the Australian wooden furniture manufacturing sector. Journal of Cleaner Production, 17(17): 1594-1602.

8. Dionco-Adetayo, E.A., 2001: Utilization of wood wastes in Nigeria: a feasibility overview. Technovation, 21 (2001): 55-60.

9. Eshun, J.F., Potting, J., Leemans, R., 2010: Inventory analysis of the timber industry in Ghan. The International Journal of Life Cycle Assessment 15(2010): 715-725.

10. Eshun, J.F., Potting, J., Leemans, R., 2012: Wood waste minimization in the timber sector of Ghana: a systems approach to reduce environmental impact. Journal of Cleaner Production 26: 67-78.

11. Fuwape, J.A., 2001: Forest resources and economic development in Ondo State. Paper presented at Ondo State economic summit, Pp. 1-15.

12. Gligoraş, D., Bor, S.A., 2015: Factors affecting the effective time consumption, wood recovery and feeding speed when manufacturing lumber using a fbo-02 cut mobile bandsaw. Wood Research 60(2) 2015: 329-338.

13. Hong, J.H., An, S., Song, K.Y., Kim, Y., Yarin, A.L., Kim, J.J., Yoon, S.S., 2019: Ecofriendly lignin nanofiber mat for protection of wood against attacks by environmentally hazardous fungi. Polymer Testing 74: 113-118.

14. Kantay, R., Köse, C., 2009: Forest warehouses and storage techniques. Istanbul University Faculty of Forestry Journal 59(1): 75-92.

15. Kalayc1, Ş., 2010: SPSS applied multivariate statistical techniques. Asil Publishing Distribution Ltd. Sti. Ankara, 426 pp.

16. Khalili, N.R., Duecker, S., Ashton, W., Chavez, F., 2015: From cleaner production to sustainable development: the role of academia. Journal of Cleaner Production 96: 30-43.

17. Komut, O., İmamoğlu, S., Öztürk, A., 2013: Blue colouration damage on Pinus sylvestris L. logs and their effects on sales price. Artvin Coruh University Journal of Faculty of Forestry 14(2): 283-291.

18. Komut, O., Öztürk, A., 2018: The effects of blue dyeing damage on the industrial processing properties of logs. Natural Disasters and Environment Journal 4 : 8-14.

19. Li, H., Lei, X., Wu, Y., Li. H., Guo, X., Wen, R., Hu, Y., 2019: Study of the discoloration behaviour of Teak wood (Tectona grandis Linn. fil.) caused by simulated sunlight. Wood Research 64(4): 625-636.

20. Loeffler, D., Anderson, N., 2018: Impacts of the mountain pine beetle on sawmill operations, costs and product values in Montana. Forest Products Journal 68(1): 15-24.

21. Örs, Y., Keskin, H., 2001: Wood Material Science. T.C. The Ministry of Industry and Commerce KOSGEB Small and Medium Industry Development and Support Administration, Castle Offset Printing, Ankara, Turkey, 183 pp.

22. Pang, S., H'ng, P., Chai, L., Lee, S., Paridahb, T., 2015: Value added productivity performance of the Peninsular Malaysian wood sawmilling industry. BioResources 10(4): 7324-7338. 
23. Sloan, S., Sayer, J.A., 2015: Forest resources assessment of 2015 shows positive global trends but forest loss and degradation persist in poor tropical countries. Forest Ecology and Management 352: 134-145.

24. Şen, S., Fidan, M. S., Alkan, E., Yaşar, Ş. Ş., 2018: Determination of certain properties of scotch pine (Pinus sylvestris L.) wood which is impregnated with boron compounds and Quechua. Wood Research 63(6): 1033-1044.

25. Todoroki, C., 2003: Accuracy considerations when optimally sawing pruned logs: internal defects and sawing precision. Nondestructive Testing and Evaluation 19(1-2): 29-41.

26. Tolvaj, L., Molnár, S., Németh, R., Varga, D., 2010: Color modification of black locust depending on the steaming parameters. Wood Research 55(2): 81-88.

27. Tunçel, S., Koç, H., 2017: The paradox of productivity in forest products industry, IV. National Forestry Congress, 15-16 November 2017; Antalya, pp. 523-529.

28. Vanzetti, N., Broz, D., Corsanoac, G., Montagnaa, J.M., 2018: An optimization approach for multiperiod production planning in a sawmill. Forest Policy and Economics 97: 1-8.

29. Yang, P., Jenkins, B.M., 2008: Wood residues from sawmills in California. Biomass and Bioenergy 32(2): 101-108.

30. Zeleniuc, O., 2008: Anti-sapstain treatment of timber for sustainable development. Pro Ligno 4(4): 41-55.

\author{
Osman Komut* \\ Gumushane University \\ Gumushane Vocational High School \\ Department of Forestry \\ 29100, Gumushane \\ TURKEY
}

*Corresponding author: osmankomut@gumushane.edu.tr 